\title{
Amerika'da Niğdeli Bir Şahsiyet (1884-1976): Nicolas P. Aghnides
}

\author{
Şenay ATAM ${ }^{1}$ ve Gülin ÖZTÜRK ${ }^{2}$ \\ $\ddot{O} z$
}

Osmanlı Devleti'nin çok uluslu yapısı ve içerisinde barındırdığı gayrimüslim unsurları kendi vatandaşı olarak değerlendirmesi bilinen bir gerçektir. Osmanlı Devleti içerisinde yaşayan gayrimüslimler bu topraklarda doğmuş, eğitim almış, çalışma hayatına başlamış, hatta bir kısmı devletin çeşitli kademelerinde önemli görevler almışlardır. Osmanlı Devleti içerisinde yaşayan gayrimüslimler genellikle ilköğrenimlerini kendi mensup oldukları cemaatin okullarında tamamlamışlardır. Böylece kendi din ve dillerinin temel esaslarını öğrenebilmişlerdir. Osmanlı Devleti’nin Tanzimat'tan sonraki süreçte gayrimüslimlere dinini değiştirmeden devlet memuru hakk1 getirmesiyle birlikte bu işlerde görev almak için Osmanlı Devleti’nin açmış olduğu okullarda da yükseköğrenimlerini sürdürmüşlerdir. Bu çalışmada Niğde gibi küçük bir Anadolu şehrinde doğup, yüksekokul için İstanbul'a gelen oradan da Osmanlı Devleti'nin açtı̆̆ bir sınav sonucu başarılı olarak yolu Amerika'ya düşen bir Rum olan Nicolas Aghnides'in biyografisi, Amerika yolculuğu ve ardında bıraktığı eserler Osmanlı ve Amerikan arşivleri kayıtlarında mevcut belgelerden de faydalanılarak incelenmiştir. Bu çalışma ile bir Osmanlı olan Aghnides'in hayatı hakkında bilgi edinirken bir yandan da onun üzerinden Osmanlının Müslüman olmayan bir Rum’u Amerika gibi bir ülkede ücretsiz eğitim alması konusundaki olumlu tavrı üzerinden 20. yüzyıl azınlık politikası hakkında da bilgi edinmek mümkün olabilecektir.

Anabtar Kelimeler: Aghnides, Niğde, Yurt Dışı Eğitim, Amerika, Colombia Üniversitesi

\section{A Person from Niğde in America (1884-1976): Nicolas P. Aghnides}

\begin{abstract}
It is a known fact that Ottoman Empire had multinational structure and deemed Non-Muslim people as their own citizens. The Non-Muslims living in the Ottoman Empire were born, educated, started to work in these lands and even some of them took important duties in various levels of the state. Non-Muslims living in the Ottoman Empire usually had their primary education in the schools of the community they belong to. Thus, they learned the basic principles of their religion and languages. Ottoman Empire gave the civil service right to the Non-Muslims during the period after the Tanzimat Reform Era, they continued their higher education in order to take duty in these jobs in the schools opened by the Ottoman Empire. In this study, biography of Nicolas Aghnides, was born in one of small cities Anatolia, Niğde, and came to Istanbul for higher education and became successful as a result of exam hold by Ottoman Empire, and went to America, his travel to America and his artworks were examined in the light of records in Ottoman and American archives. While obtaining information about Aghnides who is an Ottoman along with this study, it will be possible to obtain information related to 20th century minority policy through Ottoman's positive attitude on a Non- Muslim Greek got free training in America.
\end{abstract}

Key Words: Aghnides, Niğde, International Education, America, Columbia University

\section{Atıf İçin / Please Cite As:}

Atam, Ş. ve Öztürk, G. (2020). Amerika'da Niğdeli bir şahsiyet (1884-1976): Nicolas P. Aghnides. Manas Sosyal Arasttrmalar Dergisi, 9(2), 1260-1267.

Geliş Tarihi / Received Date: 04.03.2019

Kabul Tarihi / Accepted Date: 11.11.2019

\footnotetext{
${ }^{1}$ Dr. Öğr. Üyesi - Osmaniye Korkut Ata Üniversitesi Fen-Edebiyat Fakültesi, senayatam@osmaniye.edu.tr ORCID: 0000-0001-8672-3063

2 Doç. Dr. - Niğde Ömer Halis Demir Üniversitesi Fen-Edebiyat Fakültesi, gulinozturk51@hotmail.com ORCID: 0000-0001-5586-6627
} 


\section{Giriş}

16. yüzylıın sonlarına doğru Osmanlı Devletinin Avrupa karşısında askeri yenilgileri ve bu yenilgiler sonucundaki toprak kayıpları, bunun yanı sıra her alanda sürekli bir gelişme gösteren Avrupa'yı tanıma isteği, modernleşme sürecinde Osmanlı Devleti'nin yurt dışına öğrenci gönderme serüvenini başlatmıştır (Akpınar, 2015, s. 4). Başlangıçta askeri kurumların iyileştirilmesi ve batılı tarza getirilmesi hedef olarak belirlenmişse de alınan eğitimlerin ilerleyen zamanlarda devletin diğer birimlerine hizmet ettiği görülmüştür (Kılıç, 2017, s. 21). Osmanlı Devletinin batı teknolojisinden geri kalmasına karşılık bulunan en önemli çözüm yollarından biri eğitim kurumlarının Batı'dan alınarak Osmanlı Devleti içerisinde örneklerinin oluşturulması olmuştur. Bu aşamada yurt dışına eğitim için gönderilen öğrencilerden faydalanılması düşünülmüştür (Aslan, 2014, s. 3).

Yurt dışına öğrenci gönderme uygulaması III. Selim döneminde İshak Beyin Fransa'ya gönderilmesiyle başlamış, Osmanlı Devleti’nin yıkılışına kadar rakamsal farklar göstermekle birlikte devam etmiştir. Medresede zaman içerisinde fen bilimleri derslerinin kaldırılması ile mesleki teknik alanlarda ihtiyaç duyulan kalifiye eleman açığı ortaya çıkmıştır. Bunun neticesinde meydana gelen açık, Avrupa'ya öğrenci gönderilmek suretiyle giderilmeye çalışılmış özellikle Yeniçeri Ocağının kaldırılmasından sonra yenilik hareketlerine ağırlık veren II. Mahmut bu yaptı̆̆ı yenilikleri sürdürülebilir hale getirmek için Avrupa'ya öğrenci göndermeye devam etmiştir (Ulu, 2014, s. 495-96). Tanzimat Fermanı'nın ilanı ile birlikte yurt dışına öğrenci gönderilmesi işi ciddi olarak gündeme gelmiş ve bu nedenle de bașta Fransa olmak üzere Belçika, Avusturya, İngiltere, Macaristan, İtalya ve Almanya'ya Osmanlı Devleti, tebaası arasında herhangi bir millet ve din ayrımı yapmaksızın öğrencileri çeşitli bilim dallarında yetiştirmek üzere göndermiştir (Şişman, 2002, s. 2; Erkek, 2010, s. 762). Bu eğitim süreci II. Abdülhamit dönemine kadar devam etmiştir. Fakat Sultan II. Abdülhamit, Darülfünun'un kurulmasından hemen sonra öğrencileri Osmanl sistemine muhalifler haline getiren, ahlaken dönüşmelerine sebep olan Avrupa'dan uzak tutmak ve Osmanlı toplumsal yapısı içinde, milli ve dini değerlere uygun eğitim almalarını sağlamak düşüncesiyle öğrencilerin yurt dışına gönderilmesi uygulamasına son vermiştir. 1908 sonrasında ise İttihat ve Terakki yönetimi, diğer birçok alanda olduğu gibi, II. Abdülhamit'in uygulamasını değiştirmiş ve önceki dönemlerle karşılaştırıldığında azımsanamayacak sayıda öğrenciyi Avrupa'ya tahsile göndermiş ve böylelikle eğitim alanında batı modernizasyonunu bir üst seviyeye taşımak istemişlerdir. Bu yönetim eğitim alanında yeni bilim dalları kurmak, yabancı uzmanlar getirmek gibi uygulamaların yanında Avrupa'ya, Amerika'ya talebe göndermek suretiyle bilimsel özerklik kazanmak, Türk kültürünü araştırmak, fakülte dergileri çıkarmak, hatta Sapanca gölü civarında bir Darülfünun yerleşkesi yapmayı bile planlamışlardır. Avrupa'ya gönderilecek öğrenci sayısını artırabilmek için de batılı ülkelerle yazışmalar gerçekleştirerek kabul aldıkları ülkelere öğrenciler göndermişlerdir. Hükümetin bu öğrenci gönderme hamlesi Avrupa ülkeleri tarafindan memnuniyetle karşılanmış, her biri bu kârlı uygulamadan aldıkları paylarını artırmanın yollarını aramışlardır. Öncekilerden farklı olarak bu dönemde özellikle İtalya ve Amerika'ya da öğrenci gönderilmesi uygulaması başlatılıışır. 19. yüzyılda Amerika ile ilk ilişkiler askeri kurumlar üzerinden gerçekleştirilmeye çalışılmıştır. 1850 yılında Bahriye Mektebi öğretmeni Binbaşı Emin Bey, gemi inşaatı alanında incelemelerde bulunmak üzere Amerika'ya gitmiştir. Mehmet Paşa başkanlığındaki bir askeri heyet ise 1858 y1lında Amerikan tersanelerini gezmiştir. 1872 yılında üç kişilik bir heyetin başında giden Albay Tevfik Bey, 1876 yllına kadar Amerika'da kalmış ve Osmanlı ordusu için Martini Henry, Winchester ve Snyder tüfekleri satın almıştır (Erdoğan, 2013, s. 230-232). Bu şekilde başlayan ilişkiler Amerika'nın Osmanlı ülkesinde misyonerlik faaliyetleri ile de devam etmiştir. Bu dönemde yoğun bir şekilde Amerikan kolejleri, hastaneler gibi kuruluşlar Osmanlı ülkesinde ardı ardına açılmıştır. Daha sonra bu ilişkiler Osmanlı Devleti’nin yurt dışına öğrenci gönderimini artırdığı dönemde Amerika'nın bu ülkeler içerisinde yer almasını sağlamıştır. Osmanlı Devleti’nin Amerika’ya ilk öğrenci göndermesi 1910 yllında Amerikan sefirinin girişimleri neticesinde olmuştur. Colombia Üniversitesi ile on ylllğına her sene üç öğrencinin yüksek eğitim almak üzere Amerika'ya gönderilmesi için bir anlaşma yapılmıştır (BOA, MF MKT, 1152/11, 28 Cemaziyelahir 1328, 7 Temmuz 1910). Bu sayı daha sonra beşe çıkarılmıştır. Gönderilecek öğrencilerde aranılan şartlardan en mühimi oradaki dersleri takip edebilecek düzeyde İngilizce bilmektir.(BOA MF MKT 1152/60, 1 Rebiülahir 1328, 12 Nisan 1910; BOA MF MKT 1163/32, 25 Şevval 1328, 30 Ekim 1910; BOA MF MKT 1166/7, 25 Muharrem 1329, 26 Ocak 1911). Buraya gönderilecekleri seçmek için Maarif Nezareti’nde bir komisyon oluşturulmuş ve bu komisyona birçok başvuru yapılmıştır. (BOA MF MKT 1152/2, 28 Rebiülahir 1328, 9 Mayıs 1910, BOA MF MKT 1152/60, 29 Rebiülahir 1328, 10 Mayıs 1910; BOA MF MKT 155/95, 28 Cemaziyelahir 1328, 7 Temmuz 1910). Nikola Aghnides de bu başvuru yapan adaylar arasındadır. Aghnides başvuru dilekçesinde hukuk mektebinden yeni mezun olduğunu ve Colombia 
Üniversitesi için yapılacak sınava katılmak istediğini beyan etmiş, dilekçesinde de İstanbul Cağaloğlu'nda Nuruosmaniye'de 29 numarada ikamet ettiğini belirtmiştir (BOA MF MKT 1157/32, 30 Receb1328, 7 Ağustos 1910). Bu ilk öğrenci grubunun ardından 1919 yllında iki öğrenci daha gönderilmiș, ancak bu dönemde Osmanlı Devleti’nin Birinci Dünya Savaşı'ndan yenik bir devlet olarak ayrılması, içinde bulunduğu ekonomik ve siyasi durumlar Colombia Üniversitesi ile yapılan anlaşmanın devam ettirilememesine neden olmuștur.

Bu çalışmada amaç Müslüman bir toplumda doğup eğitim hayatını Anadolu'da tamamlayan Rum bir şahsiyetin Amerika'ya yolculuğu ve iş hayatında gelmiş olduğu zirvenin çalışmış olduğu dönemlere ait belgelere dayanan serüvenini ortaya koymaktır. Aghnides, Türkiye'de almış olduğu eğitim ile yetinmeyerek ileri derecede birçok dil öğrenmiş, özellikle de Arapça ve Kur'an-1 Kerim başta olmak üzere birçok İslami kaynağı karşılaştırmalı olarak değerlendirebilmiştir. Hazırlamış olduğu tez ile bilimsel dünyada yerini almış ve de birçok çalışmaya öncülük etmiştir.

\section{Hayat1}

Nicholas Prodromou Aghnides 1884/1885 yllında Niğde'de doğmuş, Osmanlı sicil kayıtlarına göre Niğde’nin Kayabaşı Orta Mahallesi 36 numaraya kayıtlı olduğu tespit edilmiştir. Babası Prodromos Aghnides, annesi ise Anastassia'dır. Nicholas'ın ilköğrenimini okuduğu yıllar tahminen 1890 yılına tekabül edip, ilköğrenimini Niğde'deki Rum okulunda yapmıştır. Niğde'de bu dönemde yaklaşık 18.000 Ortodoks Rum yaşamakta; Ortodoks Rumlarına ait ise iki okul bulunmaktadır (Cuinet, V. I, 1892, s. 836). Bunlardan biri kız diğeri erkek Rum okuludur. Aynı dönemde erkek okulunda 256 öğrencinin öğrenim gördüğü bilinmektedir (Doğan, 2005, s. 159). Nicholas, Rum okulunu bitirdikten sonra 1900-1903 y1lları arasında Mersin (Tarsus) Amerikan Kolejinde eğitimini sürdürmüştür (Aghnides, 1916, s. 541). 22 Kasım 1888 tarihinde açılan ve sıkı bir eğitim-öğretim programına tabi olan bu okula öğrenciler sınavla seçilerek ve ahlaken de referanslarla kayıt yaptırabilmektedir. Okulun hedefi, gerçekleri kavrayabilen, dünya meseleleriyle ilgilenebilen, aydınlık düşünceleri taşıyabilen, sorunları çözümleyebilen, önyargısız ve kararlarını iradeleri doğrultusunda verebilen gençler yetiştirebilmektir. İlk başta okula sadece Ermenilerden kayıt yaptıranlar olmuşsa da okulun eğitimdeki başarısı kulaktan kulağa yayılmış ve kısa zamanda Rumlardan da kayıt almaya başlamışlardır. Aghnides'in okuduğu dönemlerde okulda ortalama 200 öğrenci bulunmaktadır ve bunların \%75’i Ermeni, \%18’i Rum'dur (Halifeoğlu, 2007, s. 27-47).

1904 yllında İstanbul'a gelerek Kadıköy'deki Fransız St. Joseph okuluna giden Nicholas daha sonra Hukuk Mektebine devam etmiş ve 1909 yllında buradan mezun olarak 1910 yllinda bir süre avukat olarak İstanbul'da çalışmıştır (Aghnides, 1916, s. 541; Yalman, 1997, s. 130; McGrew, 2015, s. 126). (Ahmet Emin Yalman bu dönemde Osmanlı Hükümeti'nin kendisine Samsun savcilığını teklif etse de kabul etmediğini belirtmektedir.) Hukuk Mektebinden yeni mezun bir avukat olarak hayatını tamamen değiştirecek gelişme ise yukarıda da bahsedildiği gibi Osmanlı Hükümeti ile Amerikan elçisi arasında yapılan görüşmeler neticesinde Amerika'ya öğrenci gönderilmesi ile ilgili gerçekleştirilen anlaşma neticesinde ortaya çıkmıştır.

Osmanlı Hükümeti'nin Colombia Üniversitesi ile yaptığı bu anlaşma gereğince Amerika’ya gönderilecek öğrencileri seçmek için yapılan sınava yaklaşık 180 kişi katılmış; bu sınav sonucu Nicolas da Amerika'ya gitmeye hak kazanan beş kişi arasında yerini almıştır (Yalman, 1997:129).

\section{Amerika'ya Yolculuk ve Amerika'da Yaşam}

Sınav sonrası Amerika'ya gidecekler arasında Cevat Eyüp (sonraki Petrol Araştırma Müdürü, Tasmen), Abdullah Hamdi (sonraki Elektrik Etüd İdaresi Umum Müdürü, Toker), Ahmed Şükrü (Profesör, Esmer) ve gazeteci Ahmet Emin (Yalman) yer almaktadır. Ahmet Emin'in anlattıklarına göre Amerika'ya gidecek bu beş kişi Çemberlitaş'ta bir araya gelerek yola çıkış için hazırlıkları planlamışlar ve 1911 Şubat'ının ilk gününe karar vermişlerdir. Gerekli hazırlıklar yapıldıktan sonra Mauretania gemisiyle Amerika'ya yolculukları başlamıştır. Amerika'ya girişler bugün olduğu gibi o zaman da çok sıkı olduğundan Amerika'ya vardıklarında kendilerine anarşist, çok eşliliği savunan poligamist olmadıklarına ya da Amerika'da hükümeti devirmeye gelmediklerine dair bir belge imzalamaları istenmiştir. Nicholas bu belgeyi imzalamıştır (Country Naturization Record, 305, 2018). (Belge ekte yer almaktadır.) Yalman, Amerika'ya 5 Şubat'ta vardıklarını bu tarihin okulun ilk dönem kaydı için geç olduğunu bu nedenle de ilk dönemi kaybettiklerini belirtmiştir. Nicolas ise ilerleyen dönemde burada Siyasi İlimler Fakültesi'nde okumaya hak kazanmıştır (Yalman, 1997, s. 130-131). Ayrıca Colombia Üniversitesi'nde birçok hocadan ders almış, iktisat ve maliye alanında ihtisas yapmış, 1913 yllında Master derecesine kadar ulaşmıştır (Aghnides, 1916, 
s. 541). Sonrasında hocaları onun Müslüman ülkede yetişmiş, iyi derecede Türkçe bilen biri olarak İslam hukukunu incelemeye yönlendirmişlerdir. Zaten kendisi de tezinde İslam’a olan hayranlığının kendisini bu alanda uzmanlaşmaya yönlendirdiğini ifade etmiştir. İşte onun bu ilgisi "İslam Maliye Sisteminin Kaynakları"nı incelemek için Arapça öğrenmesine sebep olmuştur. Böylece birçok ana kaynağı inceleme firsatı ortaya çıkmış sonuçta bu sisteme dair doktora tezi hazırlamıştır. Doktora öğrencisi iken 1913 yılında Liverpool'a seyahat ettiği Amerikan belgelerinden anlaşılmaktadır (Family Search, 2018). 1916 yllında doktora derecesini aldıktan sonra Darmouth College'de öğretim üyeliği yapan Nicolas bir süre sigorta şirketlerinde uzman olarak çalısmış (Aghnides, 2003, s. 5) ve daha sonra ülkesine dönme kararı almıştır. Ancak bu esnada onun geleceğini etkileyecek yeni gelişme Birinci Dünya Savaşı'nın çıkmış olmasıdır. Nicolas Aghnides, Osmanlı Devleti'nin bu savaş içinde bulunduğu durum sebebiyle muhtemelen ülkesine geri dönemeyeceğini düşünmüş ve Amerika’ya kalıcı olarak yerleşmiştir. Artık Amerikalı olan Aghnides, 1917 yllında hemşire olan Rebecca Wagner ile evlenmiştir (Newyork City Marriage Records, 2018). Aghnides'in Amerika'daki nüfus kayttlarına ait bilgiler 1940 yllına kadar takip edilebilmektedir. Amerikan kayıtlarına göre 54 yaşında olan Aghnides, Manhatton'da eşi Rebecca ve kardeşi Ellie ile beraber yaşamış ve Mourance Co. (?) şirketinde çalışmıştır. Maaşını ise 1560 dolar olarak göstermiştir. Newyork'da başarılı bir yatırımcı olduğu bilgisinin dışında kardeşi Thanassis'ın Birleşmiş Milletlerde üst düzey görevlerde yer aldığı ifade edilmiştir (McGrew, 2015, s. 126). Ancak bundan sonrasına ait herhangi bir bilgi ne yazık ki bulunmamaktadır (United State Census, 1940, s. 2018).

Ahmet Emin Yalman Aghnides’i tam bir Anadolulu olarak tanımlamaktadır. Mütareke yıllarında Amerika'da işsiz kalmış, bu sıralarda Yunan Hükümeti'nin kendisini Atina’ya İslam Hukuku profesörü olarak davet etmesi üzerine ise "ben Türk parası ile Amerika'da tahsil gördüm. Türklerle Yunanlıların savaş halinde olduğu bir sırada Yunanistan'a hizmet edemem.” demiştir. 1962 yllinda memleketi Niğde'yi görmek üzere Atina'ya oradan da Türkiye'ye geçmek istemişse de Atina'daki Amerikan konsolosunun yanlış bilgi vermesi üzerine bu isteğini yerine getirememiștir (Yalman, 1997, s. 142-144). Aghnides, 1976 yllinda Amerika'da vefat etmiştir (Unites State Death İndex: Aghnides). "Mohammedan Theories of Finance- with an İntroduction to Mohammedan Law and a Bibliography" adindaki tezi "İslam'ın Mali Hükümleri” ismi ile Prof. Dr. Servet Armağan tarafından Türkçe’ye çevrilerek yayınlanmıştır. Üniversite kayıtlarına göre İslam Hukuku Uzmanı sayılan Aghnides'in, Türkçe ve Rumca dışında, çok iyi derecede Arapça, İngilizce ve Fransızca bildiği anlaşılmaktadır (Aghnides, 2001). Bu kadar dil bilmesi çok normaldir. Zaten bir Rum olduğu için Rumca ana dilidir. Türkiye topraklarında doğmuş bir gayrimüslim olarak Türkçe'de ikinci anadilidir. Osmanlıca'nın yapısı dolayısıyla Arapça'ya aşinalığı vardır. Bu nedenle de eserlerinde kullandığı kaynakların büyük bir kısmı da Arapça'dır. Amerika'ya gittiğinde bu konuda eğitim almaya başladığında alfabesini Osmanlıca'dan dolayı bildiğinden zorlanmamıştır. İngilizce ve Fransızca ise Amerikan Koleji'nde aldığı eğitim sayesinde daha Amerika'ya gitmeden öğrenmiş olduğu diğer yabanc1 dillerdir. Amerikan okullarına yönelik yapılan çalşmalardan bu okullarda çok iyi bir yabancı dil eğitim verildiği bilinmektedir. Örneğin, ilk yll hazırlık eğitimi süresince haftada beşer saat olmak üzere İngilizce, Fransızca, Türkçe, Ermenice ve Yunanca dersleri verilmektedir. Mezun olana kadar da diğer derslerin yanında yine haftada beşer saat bu dillere yönelik eğitim devam etmektedir (Halifeoğlu, 2007, s. 49-50).

\section{Eserleri}

Nicolas Aghnides'in doktora tez çalı̧̧ması olan "İslam'ın Mali Hükümleri” adlı eseri sonradan birçok kez basılmış ve Türkçe de dâhil olmak üzere başka dillere çevrilmiştir. Bu eseri kendisinden sonra birçok çalışmaya kaynaklık etmiş ayııca bu konu üzerine çalışanların da muhakkak değerlendirmesi gereken bir çalışma olmuştur. Bu tez İslam hukukunda vergi kavramı, vergi çeşitleri, özellikle arazi vergileri, vergilerin toplanmas1, vergilerin devlet hizmetlerine sarf cihetleri ile bugün Sayıştay dediğimiz bütçenin uygulanmasını kontrol ve ilgili itirazları sonuçlandırmak gibi konuları içine almaktadır. İslam hukukunun özellikle kamu maliyesi kısmını detaylı bir şekilde ele almış; İslam hukuku ile ilgili olan temel kitapların bir listesini tezinde vermeyi de ihmal etmemiştir.

Tez esas olarak iki ayrı kitap ve her kitabın içinde birçok bölümden oluşmaktadır. Birinci kitap aslında tezin ana konusu olan İslam'ın Mali Hükümlerine giriş niteliğindedir ve temel olarak İslam hukukunun ana esaslarını ortaya koymayı amaçlamaktadır. 11 bölümden oluşan bu kısımda öncelikle şeriatın ve fikıhın tanımları verilmiştir (Aghnides, 1916, s. 23-29) Ardından İslam hukukunun ana kaynakları ele alınmıştır. Kur'an, sünnet, kıyas ve icma-1 ümmet kaynakları dışında örf, istihsân ve istislâh gibi kaynakları da açıklanmıştır (Aghnides, 1916, s. 30-102). Birinci kitabın 8. bölümünde şeriat hükümlerinin sınıflandırılması başlı̆ı altında farz, vacip, sünnet, mübah, mekruh ve haram terimlerinin açıklamasını 
yapmıştır (Aghnides, 1916, s. 109-116). Dokuzuncu bölümde ise içtihat, müçtehit tanımlarını yaparak içtihat kapısının kapanıp kapanmadığına dair farklı kaynakları karşılaştırarak değerlendirmelerde bulunmuştur (Aghnides, 1916, s. 117-132). Bunlardan sonra da 10. bölümde içtihat ve mezhep ve büyük mezhep kurucularının özelliklerini anlatmaktadır (Aghnides, 1916, s. 133-147). Birinci kitabı genel değerlendirme yaparak ve sonuna oldukça geniş bir bibliyografya koyarak sonlandırmıştır. Bibliyografyada çoğunlukla Arapça kaynaklara çok az olarak da batı dillerindeki kaynaklara yer verilmiştir (Aghnides, 1916, s. 148-196).

İkinci kitapta ise Aghnides'in esas olarak incelemek istediği İslam hukukunun mali hükümleri ele alınmaktadır. Bu konuları ele alırken de açılayıcı ve anlaşılır bir üslup kullanmıştır. İslam'ın mali hukukunun temellerini açıklarken iki ana çerçevede ele almıştır. Önce gelirleri, sonrasında giderleri açıklamıştır. Gelirleri de dini gelirler ve dini olmayan gelirler şeklinde iki ana gruba ayırmıştır. Dini gelirler içerisinde zekâtı oldukça detaylı bir şekilde ele almıştır. Açıklamalarını çok doğru noktalara temas ederek yapmışıır. Örneğin, zekât konusunu sadece zekâtın tanımını yapıp, zekât mükellefi kimdir, kimler zekât alabilir? gibi klasik açıklamaların dışına çıkarak İslam devleti zekâtın neresindedir? şeklinde detaylandırarak konuyu etraflı bir şekilde ele almış ve eksik bırakmamışır. Çünkü zekât aynı zamanda İslam devletinde devlet bütçesinde bir gelir teşkil etmektedir. Yani zekâtın bir ibadet olması onu ödeyen Müslüman açısından ayrı olarak değerlendirilmesi gereken bir husustur. Modern zamanda da zekât ile ilgili yapılan çalısmaların temel sıkıntısı da budur. Aghnides, bu iki mefhumu birbirinden ayırarak zekâtı İslam devletinin gelirleri bakımından da ayrıca değerlendirmiştir. İşte onun bu bakış açısı kendisinden sonra gelenlere de 1şık tutmuş, eserinin değerinin katlanmasına ve bu konu ile ilgili yapılan hemen hemen bütün çalışmalarda görülmesi gereken bir kaynak konumuna getirmiştir.

Giderleri ise

1. Hazine ve bütçe

2. Zekat vergilerinin sarfi

3. Din dışı gelirlerin sarfi

4. Vergi imtiyazlar1

5. Devlet sicilleri

6. Kamu Malları şeklinde sınıflandırarak açıklamıştır(Aghnides, 2003: 20-21; Dilmen, Yeşilyurt, 2015, s. 338).

Aghnides'in yaptığı detaylı açıklamalarla İslam devletinin idari-mali yapısı daha belirgin olarak ortaya çıkmıştır. Kitabını İngilizce yazmış bu çalışmayı yaparken de birçok Arapça, İngilizce, Almanca, Fransızca ve Türkçe 'ye de hâkim olduğundan yer yer Türkçe kaynaklardan faydalanmıştır. Konu ile ilgili destekleyici olarak ayet ve hadis kullanmayı da ihmal etmemiştir.

Aghnides’in çalışması Amerika dışında da çok ses getirmiş ve tezi üzerinde daha o dönemde bile değerlendirme yapanlar olmuştur (Mannan, 1973, s. 385-389). Değerlendirme yapanların en önemlilerinden birisi Aghnides'in çağdaşı İslam hukuku araştırmacısı ve "The Principles of Muhammadan Jurisprudence" kitabının yazarı Abdür Rahim'dir. (Abdur Rahim, 1911). Abdur Rahim, Aghnides'in çalışmasının, kendi alanında birçok anlaşılması güç olan kısımları kolayca açıkladığını ifade etmiş ve üstünlüğünün konuları temel kaynaklara dayandırmasından geldiğini belirtmiştir. Abdür Rahim'in Aghnides'in teziyle ilgili eleştirisi ise Arapça hukuki ifadelerin çok basit bir çevirisine sadık kalarak sıradan bir okuyucunun tartışmalarını takip etmesini gereksiz yere zorlaştırdığına yönelik olmuştur (Abdur Rahim, 1921, s. 97-99). Martin Sprengling ise bu çalışmanın bir başucu kitabı olacağına özellikle vurgu yapmıştır (Sprelling, 1918, s. 211213). Yine aynı dönemde Almanya'da da bu çalşsmanın incelendiğini görmek mümkündür (Goldhizer, 1917, s. 438-44).

\section{Tartı̧̧ma, Sonuç ve Öneriler}

1883 yllında Niğde'de başlayıp, 1976 yllında Amerika'da son bulan bir hayatın sahibi olan Aghnides, hem bu özelliği bakımından hem de geride bırakmış olduğu eseri bakımından incelemeye değer bir şahsiyettir. Anadolulu olma özelliğini hayatının sonuna kadar üzerinde taşımış, ülkesine bir gün dönebilmenin hasretini çekmiştir. Onun Osmanlı topraklarında başlayan eğitim hayatı, Amerika'da zirve noktasına erişmiştir. Müslüman bir toplumda doğup büyüyen bir Hristiyan olması, ona tezini hazırlarken yabancılık çekebileceği terimleri gayet rahatlıkla açılayabilmesine yardımcı olmuştur. Tabi bunu yaparken 
sadece Türkiye'de gördükleri ile yetinmeyerek ileri derecede Arapça öğrenmiş ve Kur'an-1 Kerim başta olmak üzere birçok İslami kaynağı karşılaştırmalı olarak değerlendirebilmiştir. Amerika'ya giderken aklında böyle bir tez hazırlama kaygısı var mıydı bilinmez. Ancak Colombia Üniversitesi'ndeki hocalarının onun bu özelliğinden faydalanmayı bildikleri ve onu bu konuya yönlendirdikleri akla yatkın bir ihtimaldir. Böylece muhteşem aynı zaman da bu konu üzerine çalışma yapanların başvuracağı ana kaynaklardan biri olacak bir tez ortaya çıkmıştır. Nicholas doğduğu topraklarda bizzat Müslümanlarla iç içe büyümüş olduğundan İslam'a bir gayrimüslim gözüyle dışarıdan bakabilmiş, bunu yaparken İslam aleyhtarı bir tavır sergilememiştir. Objektif bir şekilde eserini hazırlamış olması da eserin üstünlüğünü bir kat daha artırmışır.

\section{Etik Beyan}

“Amerika'da Niğdeli Bir Şahsiyet (1884-1976): Nicolas P. Aghnides” başlıklı çalısmanın yazım sürecinde bilimsel, etik ve alıntı kurallarına uyulmuş; toplanan veriler üzerinde herhangi bir tahrifat yapılmamıs ve bu çalışma herhangi başka bir akademik yayın ortamına değerlendirme için gönderilmemiştir.

\section{Kaynakça}

\section{A-Arşivler}

Başbakanlık Osmanlı Arşivi (BOA)

MF MKT (Maarif Nezareti Mektubi Kalemi Belgeleri)

Nr. 1152/11, 1152/60, 1163/32, 1152/21, 1155/95, 1157/32, 1166/7

DH SN THR (Dahiliye Nezareti Sicil-i Nüfus Tahrirat Kalemi Belgeleri)

Nr. 4/40

\section{B-Diğer Eserler}

Abdur Rahim. (1921). Reviewed Work(s): Mohammedan Theories of Finance. by Nicholas P. Aghnides, The Economic Journal, 31, London, 97-99.

Abdur Rahim. (1911). The Principles of Muhammadan Jurisprudence, Madras.

Aghnides, N. P. (1911). Mohammedan Theories of Finance, Newyork.

Aghnides, N. P. (2003). İslâm'ın Mâlî Hükümleri, (Çev. Servet Armağan), İstanbul, İnsan.

Aghnides, N. P., İslâm Hukukuna Giriş, (Çev. Servet Armağan), İstanbul, Beta.

Akpınar, B. (2015). Modernleşme Aracı Olarak Yurt Dışı Öğrenciler: Bitmeyen Serüven, Eğitime Bakış, 34, Ankara, 4-10.

Aslan, C. (2014). Erken Cumhuriyet Dönemi’nde Eğitim Bilimleri alanında Yurt Dıșına Öğrenci Gönderilmesi Olgusu (1923-1940), Ankara Üniversitesi Eğitim Bilimleri Enstitüsü Basılmamış Doktora Tezi, Ankara.

Cuinet, V. (1892). La Turquie D'Asie, V. I, Paris.

Doğan, H. (2005).Seyahatnamelere Göre Niğde, Niğde Tarihi Üzerine, İstanbul, Kitabevi.

Dökmen, G.-Yeşilyurt, Ş. (2015). "Din ve Ekonomi Bağlamında İslam Maliye Sistemi ve Günümüz Maliye Sistemiyle Karşılaştırılması, Sakarya Universitiy, international Congress on Islamıc Economics and Finance, 21-23 October, Sakarya, 331-347.

Erdoğan, A. (2013). Yurt Dişı Eğitim ve Türk Modernleşmesi, İstanbul Üniversitesi Sosyal Bilimler Enstitüsü Basılmamamış Doktora Tezi, İstanbul, 230-232.

Erkek, M. S. (2010). II. Meşrutiyet Dönemi’nde Avrupa’ya Gönderilen Osmanlı Talebeleri, XVI. Türk Tarih Kongresi, Ankara, 761-781.

Goldhizer, I. (1917). Aghnides, Mohammedan Theories of Finance, Zeitschrift der Deutschen Morgenländischen Gesellschaft, 71, Deutsche, 438-444.

Halifeoğlu, M. (2007). Tarsus Amerikan Koleji'nin Kuruluşu, Gelişimi ve Faaliyetleri, Basılmamış Yüksek Lisans Tezi, Elazı̆̆.

Kılıç, F.-Güçin, G. (2017). Cumhuriyetin İlk Yıllarında Tarih Alanında Yurt Dışına Gönderilen Öğrenciler ve Türk Tarihçiliğine Etkileri, Tarih Okulu Dergisi, XXXII, 19-54.

Mannan, M.A.. (1973). İslam Ekonomisi Teorik ve Pratik, İstanbul, Fikir.

McGrew, W. (2015). Educating Across Culteres, Anatolia College in Turkey and Greece, London, Rowman and Littlefield.

Sprengling, M. (1918). Reviewed Work(s): Mohammedan Theories of Finance by Nicolas P. Aghnides, The American Journal of Semitic Languages and Literatures, 34, Chicago, 211-213.

Şişman, A. (2003). Yurt Dışında Tahsil Yapan Burslu Ermeni Asıllı Osmanlı Öğrencileri, Afyon Kocatepe Üniversitesi Sosyal Bilimler Dergisi, 4, 1-30.

Ulu, C. (2014). 1416 Sayılı "Ecnebi Memleketlere Gönderilecek Talebe Hakkında Kanun” ve Cumhuriyetin İlk Yıllarındaki Uygulamaları, Tarih Okulu Dergisi (TOD), XVII, 495-525.

Wilson, R. (2004). The Development of Islamic Economics Theory and Practice, Islamic Thought in the Twentieth Century, Ed. Suha Taji-Farouki, Basheer M. Nafi, London, Tauris, 195-221.

Yalman, A. E. (1997). Gördüklerim ve Geçirdiklerim (1888-1918), C. I, İstanbul, Pera. 


\section{C-Online Kaynaklar}

New York, County Naturalization Records, 1791-1980 New York Declarations of intention, vol 305, no 149736150235; (https://www.familysearch.org (erişim tarihi 21.11.2018, saat 12:22)

https://www.familysearch.org (erişim tarihi 21.11.2018, saat 12:22).

New York City Marriage Records, 1829-1940, https://www.familysearch.org (erişim tarihi 21.11.2018, saat 12:22).

United States Census, 1940, New York City, Manhattan, Assembly District 22, 31-1890, https://www.familysearch.org (erişim tarihi 21.11.2018, saat 12:22).

United States Social Security Death Index, Nicolas Aghnides, https://www.familysearch.org (erişim tarihi 21.11.2018, saat 12:22).

\section{EXTENDED ABSTRACT}

In Ottoman Empire, sending students to abroad started with sending Mr. Ishak to France in Selim III era, and continued until the subversion of the Ottoman Empire with differences in the numbers of sent people. Over time, with the removal of the science courses in the madrasah, qualified employee, needed in professional technical fields, opening is arose. As a result, this opening was tried to eliminated by sending students to Europe. Mahmud II, who gave weight to reforms especially after the disbandment of the Janissaries, continued to send students to Europe in order to make his reforms sustainable. This practice, which was continued with a slight decrease in Abdul Hamid II era, has again given weight to in Committee of Union and Progress era. In the Committee of Union and Progress era, many students have sent to abroad mainly to Europe. In this era, United States were firstly included in the countries that students sent to. As a result of the attempts of the US ambassador, an agreement about sending three students every year for ten years to get higher education between Columbia University and the Ottoman State. This number then increased to five. The most important qualities that are seek in students is knowing English in the level to be able to follow the courses in there. A commission was created in Board of Education to choose the students, who will be send, and lots of applications is made to this commission. Nicolas Aghnides is among these applicants. Nicholas Prodromou Aghnides was born in Niğde in 1884/1885. In Ottoman records, he is registered in Kayabaş1 Orta Neighborhood of Niğde in number 36. His father is Prodromos Aghnides and his mother is Anastassia. He completed his primary education at the Greek school in Niğde. After he graduated from the Greek school, he continued his education in Mersin (Tarsus) American College in 1900-1903. In 1904, he came to Istanbul and went to French St. Joseph school in Kadiköy, then continued to Law School and graduated from here in 1909. In 1910, he worked in Istanbul as a lawyer. And in 1911, he entered the exam, which was made in order to choose the students that will sent to US as pursuant to the agreement between Ottoman Government and Columbia University, and he became qualified to go to the US by included among the five people to be sent. Nicolas, who arrived US in the first week of the February, was qualified to study in Political Sciences Faculty. He received lectures from the many teachers in Columbia University, and specialized in economy and finance, and received Master degree in 1913. After that, his teachers directed him to examine Islamic Law, because he was raised in a Muslim country and has great command on Turkish. He has already stated in his thesis that his admiration for Islam directed him into become specialized in this field. He prepared a doctoral thesis about this system with examining many main sources. The work of Nicolas Aghnides called Mohammedan Theories of Finance then printed for many times and translated into other languages including Turkish. In addition, his work has also been used as source for the successor works. This thesis includes subjects such as the tax concept in Islamic law, tax types, especially the land taxes, collection of the taxes, expense ways of these taxes to state services with controlling the budget that we called Court of Accounts and resulting the relevant objections. Mainly the thesis consists of two separate books and many chapters in every book. The first book is actually an introduction to the Mohammedan Theories of Finance, which is the main subject of the thesis, and aims to reveal the main principles of the Islamic law. In this part, which consists of 11 chapters, firstly the definitions of sharia and fiqh were given. Then the main sources of Islamic law were discussed. Sources such as manners, juristic preferences and reclamation were explained apart from Qur'an, sunna, Qiyas and Ijma. In the 8th chapter of the first book, he explained the terms fard, wajib, sunna, mubah, makruh and haram under the title of classification of sharia provisions. And in the 9th chapter, he made ijtihad and mujtahids and made evaluations by comparing the different sources on the subject of ijtihad. After that, he explains the characteristics of ijtihad and communion and the great communion founders. He ended the first book with making a general evaluation and adding a wide bibliography. In bibliography, there is mostly Arabic sources and a few western language sources. And in the second book, Aghnides examines the Theories of Finance of Islamic Law, which he actually wanted to examine. When he examining these, he used an explanatory and 
understandable way. He used two frames when explaining the basis of the Islam's financial law. He first explained the incomes and then the expenses. He separated the incomes as religious incomes and nonreligious incomes. He explained zakat, among the religious incomes, quite detailed. With the detailed explanations of Aghnides, Islamic state's administrative-financial structure was revealed clearly. He wrote his book in English. The work of Aghnides highly influenced also outside the US and there were people who made evaluations about his thesis even in that period. Therefore, his education life, which started in Ottoman lands, reached its peak point in the US. Being a Christian, who was born and raised in a Muslim community, helped him explain easily the terms, which he can have a hard time explaining it when he was preparing his thesis. Of course while he was doing this, he was not settled with the things that he saw in Turkey, he learned Arabic and be able to evaluate many Islamic sources, especially the Qur'an, comparatively. Because Nicholas was grew in the land that he was born with Muslims, he was able to look Islam as an outsider, a non-Muslim, and did not adopt a negative attitude towards Islam. He prepared his work objectively. His work was translated by Prof. Dr. Servet Armağan with the name İslâmın Mâli Hükümleri (Mohammedan Theories of Finance). 